\title{
A new tool for estimating liver cancer risk after a hepatitis $\mathbf{C}$ virus cure
}

\author{
Hamish Innes ${ }^{1}$, William L. Irving ${ }^{2}$ \\ ${ }^{1}$ School of Health and Life Sciences, Glasgow Caledonian University, Glasgow, UK; ${ }^{2}$ NIHR Nottingham Biomedical Research Centre, Nottingham \\ University Hospitals NHS Trust and the University of Nottingham, Nottingham, UK \\ Correspondence to: Hamish Innes. School of Health and Life Sciences, Glasgow Caledonian University, Glasgow, UK. Email: hamish.innes@gcu.ac.uk. \\ Comment on: Pons M, Rodriguez-Tajes S, Esteban JI, et al. Non-invasive prediction of liver-related events in patients with HCV-associated \\ compensated advanced chronic liver disease after oral antivirals. J Hepatol 2020;72:472-80.
}

Submitted Feb 20, 2020. Accepted for publication Mar 01, 2020.

doi: 10.21037/hbsn.2020.03.08

View this article at: http://dx.doi.org/10.21037/hbsn.2020.03.08

Chronic hepatitis $\mathrm{C}$ virus (HCV) infection frequently leads to liver cirrhosis (1), which is a major risk factor for hepatocellular carcinoma (HCC) and liver failure. Together, these two complications account for nearly half a million HCV-related deaths every year, world-wide (2). In contrast to other blood borne viruses such as HIV and hepatitis $\mathrm{B}$, chronic $\mathrm{HCV}$ is a curable infection. Yet until recently, few HCV cirrhosis patients were able to achieve a cure because standard-of-care therapies were ineffective $(<30 \%$ chance of cure) and entailed significant adverse effects (3). The arrival of direct acting antiviral (DAA) therapies has turned this situation full-circle. By directly interfering with the HCV lifecycle, DAA regimens cure more than $95 \%$ of cirrhosis patients in 8-12 weeks (4). Adverse effects are minimal. Thus, since the availability of DAAs from circa 2014-2015, the number of cirrhosis patients who have achieved a cure has increased dramatically. But an $\mathrm{HCV}$ cure is not a panacea; patients with cirrhosis who achieve a cure still remain at increased risk of developing HCC (5). Consequently, clinical guidelines recommend that all patients should continue to receive bi-annual ultrasound screening indefinitely after a cure. Screening can detect HCC at an incipient stage when prognosis is most favourable, but conversely, it is can also cause harm vis-a-vis false positive findings and unnecessary follow-up investigations (6). Thus, there is a growing appetite among clinicians to move towards a more individualised approach to HCC, i.e., targeting those who stand to gain the most from screening as opposed to patients who stand to benefit minimally or not at all. But to achieve this, robust risk stratification tools are needed.

It is against this backdrop therefore, that Pons et al., in a recent Fournal of Hepatology study, have created a new HCC risk profile tool for cured HCV patients (7). Their tool takes information about a patient's liver stiffness measurement (LSM) 1 year after completing treatment + their pretreatment albumin level, and then converts that information into a 1-, 2- and 3-year predicted risk of HCC. It was created from analysing HCC incidence data in a cohort of 572 patients with "advanced compensated chronic liver disease" who have achieved an HCV cure. Advanced compensated chronic liver disease-which can be considered as broadly equivalent to compensated liver cirrhosis (8) —was defined on the basis of a pre-treatment fibroscan score $\geq 10 \mathrm{kPa}$ with no prior history of decompensation (ascites, bleeding varices, encephalopathy or jaundice). All patients were treated at 1 of 2 hospitals in Barcelona, and were followed-up for 2.8 years on average post-cure. During this follow-up period, 25 patients developed HCC, equating to an incidence rate: 1.5 events per 100 person years. Using regression analysis, the authors assessed a total of 27 candidate predictors for association with HCC incidence. Only two of these predictors were significantly associated in multivariate analysis at $\mathrm{P}<0.05$. These were: (I) baseline albumin, and (II) liver stiffness 1 year after starting therapy. On the basis of these two variables, the authors divided patients into four risk groups, and observed distinct HCC risk profiles in each, i.e., from a HCC incidence rate of 0.9 per 100 person years (for patients with albumin $>4.4$; and LSM $<10 \mathrm{kPa}$ ) to a HCC incidence rate of 3.7 per 100 person years (for patients with albumin $<4.4 \mathrm{~g} /$ 
$\mathrm{dL}$, and $\mathrm{LSM}>10 \mathrm{kPa}$ ).

Previous studies report that most patients exhibit a rapid improvement in routine liver blood tests [e.g., platelet counts, alanine aminotransferase (ALT), aspartate aminotransferase (AST), fibrosis-4 (FIB-4); AST to Platelet Ratio Index (APRI)] and LSM immediately after achieving a cure (9). But some patients do not, and some patients worsen. It is intuitive to surmise that, ceteris paribus, a patient who exhibits improvement in LSM/platelet counts/ ALT levels, may have a better prognosis versus a patient who does not. But history tells us that what is intuitive and what is correct are not always one and the same! Thus, a key strength of Pons et al.'s study is that, to an extent, they were able to empirically test this hypothesis. Specifically, they assessed whether a patient's change in liver stiffness between starting treatment and achieving a cure, is useful as a prognostic factor for subsequent HCC risk. Amongst patients in their cohort, the mean LSM was $20.2 \mathrm{kPa}$ at the start treatment and $13.9 \mathrm{kPa} 1$ year after completing therapy. Overall, $57 \%$ of the HCC cases exhibited $>20 \%$ improvement in LSM versus $71 \%$ of the controls/noncases. But in univariate Cox regression analysis, LSM improvement was not significantly associated with subsequent HCC incidence $(\mathrm{P}=0.131)$, and on this basis, the authors did not consider it further. So, does this mean that change in prognostic factors such as LSM and liver blood tests should not be explored further? No. Because of their small sample size, the non-significant result observed could reflect a type 2 error as opposed to a true null effect (see later discussion on statistical limitations). Interestingly, two very large overlapping studies based on cured $\mathrm{HCV}$ patients from the US Veterans cohort have just been published; both indicate that improvement in FIB-4/APRI score, is a very strong predictor of HCC risk following an HCV cure $(10,11)$ More research in this territory is needed.

Another strength of Pons et al.'s study is that they provide data on the rate of incident decompensation among cured patients with advanced compensated chronic liver diseasesomething for which there has been scant data thus far. On this front, the authors indicate that five patients developed decompensation during follow-up (defined as ascites, encephalopathy, bleeding varices, or jaundice), equating to an event rate of 0.34 events per 100 person years. This suggests that incidence rate of de novo decompensation is relatively low following cure, and much less frequent than incident HCC. But more data on this front are needed.

The Pons et al. study has limitations as well as strengths. Firstly, their sample size of 572 is small insofar as only 30 patients developed an outcome of interest ( 25 with HCC and 5 with decompensation). As a rule, prognostic models developed from small sample sizes do not perform as well when tested on independent datasets. The low number of events is likely to have hampered the identification of bona fide predictors of HCC development. For example, in univariate analysis, the authors initially considered 27 prognostic factors for association with HCC incidence, and selected only four that were significant at $\mathrm{P}<0.1$ for consideration in multivariate analysis. But it is possible, that some or many of the 23 prognostic factors that were not selected for multivariate analysis, may nevertheless be important, but were not identified only because of inadequate statistical power, as opposed to a true lack of predictive value (i.e., type 2 error). Also, whilst assessing the predictive power of LSM 1 year after completing therapy (as opposed to prior to treatment initiation) is a commendable idea., arguably the authors should have considered this as a time-updated variable, or started their model at the later 1-year follow-up time point (as opposed to starting their model at the point of completing treatment). Including covariates in a Cox regression model that were measured after time zero, violates a basic rule of survival analysis (12) Another weakness is that the authors do not report the predictive performance of their HCC tool in the terms of the C-statistic or any other standard measures of model performance. This stops us from comparing its performance to alternative prediction models available such as the US Veteran Affairs HCC models (13) or the Toronto HCC Risk Index (14). So as things stand, we have no idea which model is the more accurate.

All in all, the study by Pons et al. advances our understanding into the predictors of liver-related events following an HCV cure in patients with compensated cirrhosis. The authors have created a visual tool that clinicians can use to predict a patient's $1-3$-year risk of HCC. But we would suggest that it should be used with caution for now, until its performance/accuracy has been externally validated on an independent set of patients.

\section{Acknowledgments}

Funding: None.

\section{Footnote}

Provenance and Peer Review: This article was commissioned by the editorial office of Hepatobiliary Surgery and Nutrition. 
The article did not undergo external peer review.

Conflicts of Interest: Both authors have completed the ICMJE uniform disclosure form (available at http://dx.doi. org/10.21037/hbsn.2020.03.08). The authors have no conflicts of interest to declare.

Ethical Statement: The authors are accountable for all aspects of the work in ensuring that questions related to the accuracy or integrity of any part of the work are appropriately investigated and resolved.

Open Access Statement: This is an Open Access article distributed in accordance with the Creative Commons Attribution-NonCommercial-NoDerivs 4.0 International License (CC BY-NC-ND 4.0), which permits the noncommercial replication and distribution of the article with the strict proviso that no changes or edits are made and the original work is properly cited (including links to both the formal publication through the relevant DOI and the license). See: https://creativecommons.org/licenses/by-nc-nd/4.0/.

\section{References}

1. Freeman AJ, Dore GJ, Law MG, et al. Estimating progression to cirrhosis in chronic hepatitis $\mathrm{C}$ virus infection. Hepatology 2001;34:809-16.

2. GBD 2015 Mortality and Causes of Death Collaborators. Global, regional, and national life expectancy, all-cause mortality, and cause-specific mortality for 249 causes of death, 1980-2015: a systematic analysis for the Global Burden of Disease Study 2015. Lancet 2016;388:1459-544.

3. Thomson BJ, Kwong G, Ratib S, et al. Response rates to combination therapy for chronic HCV infection in a clinical setting and derivation of probability tables for individual patient management. J Viral Hepat 2008;15:271-8.

4. Asselah T, Marcellin P, Schinazi RF. Treatment of hepatitis $\mathrm{C}$ virus infection with direct-acting antiviral agents: $100 \%$ cure? Liver Int 2018;38 Suppl 1:7-13.

Cite this article as: Innes H, Irving WL. A new tool for estimating liver cancer risk after a hepatitis $\mathrm{C}$ virus cure. Hepatobiliary Surg Nutr 2020;9(6):791-793. doi: 10.21037/ hbsn.2020.03.08
5. El-Serag HB, Kanwal F, Richardson P, et al. Risk of hepatocellular carcinoma after sustained virological response in Veterans with hepatitis $\mathrm{C}$ virus infection. Hepatology 2016;64:130-7.

6. Atiq O, Tiro J, Yopp AC, et al. An assessment of benefits and harms of hepatocellular carcinoma surveillance in patients with cirrhosis. Hepatology 2017;65:1196-205.

7. Pons M, Rodriguez-Tajes S, Esteban JI, et al. Non-invasive prediction of liver-related events in patients with $\mathrm{HCV}$ associated compensated advanced chronic liver disease after oral antivirals. J Hepatol 2020;72:472-80.

8. de Franchis R; Baveno VI Faculty. Expanding consensus in portal hypertension: Report of the Baveno VI Consensus Workshop: Stratifying risk and individualizing care for portal hypertension. J Hepatol 2015;63:743-52.

9. Knop V, Hoppe D, Welzel T, et al. Regression of fibrosis and portal hypertension in $\mathrm{HCV}$-associated cirrhosis and sustained virologic response after interferon-free antiviral therapy. J Viral Hepat 2016;23:994-1002.

10. Kanwal F, Kramer JR, Asch SM, et al. Long-Term Risk of Hepatocellular Carcinoma in HCV Patients Treated With Direct Acting Antiviral Agents. Hepatology 2020;71:44-55.

11. Ioannou GN, Beste LA, Green PK, et al. Increased Risk for Hepatocellular Carcinoma Persists Up to 10 Years After HCV Eradication in Patients With Baseline Cirrhosis or High FIB-4 Scores. Gastroenterology 2019;157:1264-78.e4.

12. Altman DG, De Stavola BL, Love SB, et al. Review of survival analyses published in cancer journals. Br J Cancer 1995;72:511-8.

13. Ioannou GN, Green PK, Beste LA, et al. Development of models estimating the risk of hepatocellular carcinoma after antiviral treatment for hepatitis C. J Hepatol 2018;69:1088-98.

14. Sharma SA, Kowgier M, Hansen BE, et al. Toronto HCC risk index: a validated scoring system to predict 10year risk of HCC in patients with cirrhosis. J Hepatol 2018;68:92-9. 